\title{
2012s-01
}

\section{Bubbles and Experience: An Experiment with a Steady Inflow of New Traders}

\author{
Huan Xie, Jipeng Zhang
}

\begin{tabular}{c}
\hline Série Scientifique \\
Scientific Series
\end{tabular}

\section{Montréal}

Janvier 2012

(C) 2012 Huan Xie, Jipeng Zhang. Tous droits réservés. All rights reserved. Reproduction partielle permise avec citation du document source, incluant la notice (C).

Short sections may be quoted without explicit permission, if full credit, including (C notice, is given to the source.
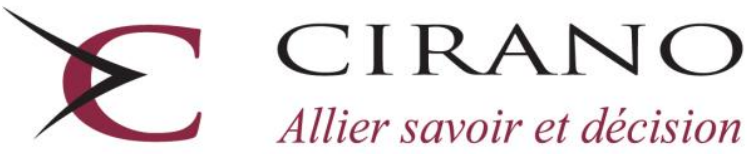

Allier savoir et décision

Centre interuniversitaire de recherche en analyse des organisations 


\section{CIRANO}

Le CIRANO est un organisme sans but lucratif constitué en vertu de la Loi des compagnies du Québec. Le financement de son infrastructure et de ses activités de recherche provient des cotisations de ses organisations-membres, d'une subvention d'infrastructure du Ministère du Développement économique et régional et de la Recherche, de même que des subventions et mandats obtenus par ses équipes de recherche.

CIRANO is a private non-profit organization incorporated under the Québec Companies Act. Its infrastructure and research activities are funded through fees paid by member organizations, an infrastructure grant from the Ministère du Développement économique et régional et de la Recherche, and grants and research mandates obtained by its research teams.

\section{Les partenaires du CIRANO}

\section{Partenaire majeur}

Ministère du Développement économique, de l'Innovation et de l'Exportation

\section{Partenaires corporatifs}

Autorité des marchés financiers

Banque de développement du Canada

Banque du Canada

Banque Laurentienne du Canada

Banque Nationale du Canada

Banque Royale du Canada

Banque Scotia

Bell Canada

BMO Groupe financier

Caisse de dépôt et placement du Québec

\section{CSST}

Fédération des caisses Desjardins du Québec

Financière Sun Life, Québec

Gaz Métro

Hydro-Québec

Industrie Canada

Investissements PSP

Ministère des Finances du Québec

Power Corporation du Canada

Rio Tinto Alcan

State Street Global Advisors

Transat A.T.

Ville de Montréal

\section{Partenaires universitaires}

École Polytechnique de Montréal

HEC Montréal

McGill University

Université Concordia

Université de Montréal

Université de Sherbrooke

Université du Québec

Université du Québec à Montréal

Université Laval

Le CIRANO collabore avec de nombreux centres et chaires de recherche universitaires dont on peut consulter la liste sur son site web.

Les cahiers de la série scientifique (CS) visent à rendre accessibles des résultats de recherche effectuée au CIRANO afin de susciter échanges et commentaires. Ces cahiers sont écrits dans le style des publications scientifiques. Les idées et les opinions émises sont sous l'unique responsabilité des auteurs et ne représentent pas nécessairement les positions du CIRANO ou de ses partenaires.

This paper presents research carried out at CIRANO and aims at encouraging discussion and comment. The observations and viewpoints expressed are the sole responsibility of the authors. They do not necessarily represent positions of CIRANO or its partners. 


\title{
Bubbles and Experience: An Experiment with a Steady Inflow of New Traders"
}

\author{
Huan Xie ${ }^{\dagger}$, Jipeng Zhang ${ }^{*}$
}

\section{Résumé / Abstract}

We revisit the effect of traders' experience on price bubbles by introducing either one-third or two-thirds steady inflow of new traders in the repeated experimental asset markets. We find that bubbles are not significantly abated by the third repetition of the market with the inflow of new traders. The relative importance of experience to the formation of bubbles depends on the proportion of new traders in the market. Our findings identify a market environment where experience is not sufficient to eliminate price bubbles.

Mots clés / Keywords: Price bubbles, experience, inflow of new traders, experiments

\footnotetext{
* We thank John Duffy, Michael Kirchler, Quang Nguyen, Yohanes Eko Riyanto, Guiying Laura Wu, and the paricipants at the ESA 2011 Asia-Pacific Meeting and the seminar participants at Lingnan University, Nanyang Technological University, Shanghai Jiaotong University, and Zhejiang University for helpful comments. We thank Xiao Liu for her invaluable research assistance and Yanyan Wu for her help in conducting the experiment. The staff support from the experimental economics laboratory at CIRANO is gratefully acknowledged.

${ }^{\dagger}$ Concordia University and CIRANO, Montréal, Canada, huanxie@ alcor.concordia.ca.

† Nanyang Technological University, Singapore, jpzhang@ntu.edu.sg.
} 


\section{Introduction}

Bubble is an important phenomenon because of its possible catastrophic consequence to the economy and society. Many studies on price bubbles rely on experimental markets that have the advantage over the real asset markets in measuring the fundamental values and price bubbles of assets. Starting from the classic work by Smith, Suchanek, and Williams (1988), numerous experimental studies have demonstated that bubbles and large price deviation exist in a variety of experimental settings. ${ }^{1}$ Another robust finding is that experience in a stationary market environment can attenuate the divergence of price expectations and reliably eliminate price bubbles, e.g., Haruvy, Lahav, and Noussair (2007). Dufwenberg, Lindqvist, and Moore (2005) (DLM, hence forth) report an experiment in which the same cohort of six subjects participate in the first three 10-period markets and some of the subjects are randomly selected and replaced by new inexperienced traders in the fourth market. They find that, in an environment with a mixture of experienced and inexperienced traders, even with as small a fraction of experienced traders as one-third, bubbles are substantially abated.

The effect of experience and learning on bubbles, however, appears very different from the evidence in empirical studies. Xiong and Yu (2011) find no evidence of investor learning in alleviating asset bubbles, using data from the Chinese warrants market. They split their data sample, which spans over three years, into two halves that have investors with different levels of learning, and find that the differences between these two subsamples in warrants prices, turnover, volatility, and the magnitude of violating the fundamental upper bound are insignificant. Moreover, some studies show that inexperienced investors play an important role in the formation of price bubbles. Greenwood and Nagel (2009) find that, using age as a proxy for experience, around the peak of the technology stock bubble, mutual funds run by younger managers are more heavily invested in technology stocks than their older colleagues, and young managers, but not old one, exhibit trend-chasing behavior in their investments.

The different findings from the lab and the field studies might relate to their differences in the inflow of new traders and the composition of traders with different experience level. In most of the experimental studies, it is the same set of traders that interact with each other over time; the experienced traders gain common group experience (Hussam, Porter and Smith, 2008). Nevertheless, in the real asset market, there is always a continuous inflow of new (inexperienced) traders, especially during the booming period of a market during which bubbles are also more likely to form. As shown by Seru, Stoffman and Shumway (2010), investor attrition is a key factor to understand investors' learning by trading. The different composition of traders may have an influence on traders' expectations and behavior, and then leads to different findings on the effect of experience on bubbles.

In this study, we revisit the relationship between experience and bubbles by investigating the effect of the steady inflow of new traders on the formation of price bubbles, simply noted as the "new-trader effect," in contrast to the experience/learning effect. In particular, we adopt an experimental design that introduces a steady inflow of new traders. Thus, in each market, we have a composition of

\footnotetext{
${ }^{1}$ For example, Mark Van Boening, Arlington W. Williams, and Shawn LaMaster (1993) employ call market instead of double auction to decide the trading; King, Ronald R., Smith, Vernon L., Williams, Arlington W. and Van Boening, Mark V. evaluate the effect of buying on margin and professional traders, Vernon Smith, Mark van Boening, and Charissa P. Wellford (2000) use assets with constant fundamental values instead of declining values; Vivian Lei, Charles N. Noussair, and Charles R. Plott (2001) investigate buy-only and sell-only constaints and the impact of introducing a parallel commodity market; Ernan Haruvy and Charles N. Noussair (2006) study the impact of short-selling; Stöckl, Thomas, J. Huber, and Michael Kirchler (2010) investigate the comparability of different bubble measures.
} 
experienced and inexperienced traders, mimicing more closely the real asset market. Different from previous experimental studies, the experienced traders in our study gain experience through continual interaction with different new traders. Furthermore, by varying the number of new traders who enter a market, we can examine the interaction and the relative importance of the new-trader effect and the classic experience effect.

Our experimental design involves three treatments. The baseline treatment is similar to the design in DLM, where new traders only exist in the last (fourth) repetition of the market. In our "inflow" treatments, denoted as "Inflow $1 / 3$ " or "Inflow $2 / 3$ ", we replace either $1 / 3$ or $2 / 3$ of the traders with new traders after each of the repeatedly operated experimental markets, while keeping a fixed group of experienced traders and the same market size.

We find that bubbles are not substantially abated and most bubble measures have no statistical difference over the repetition of the asset markets, in both inflow treatments. On the opposite, in the baseline treatment, bubbles are significantly abated by the third repetition of the market and adding new traders in the fourth market does not affect price bubbles, the same as what DLM have found. These findings demonstrate that the steady inflow of new traders can sustain bubbles even with the existence of as much as two-thirds experienced traders in the market.

Naturally, an interesting question is why the steady inflow of new traders changes the pricing dynamics and how the learning effect interacts with the new-trader effect. We find that the learning effect is most significant in the baseline treatment, in which the common group experience of traders leads to significant alleviation of bubbles by the third repetition of the market. In the inflow treatments, however, the learning effect has less impacts on price bubbles because of the new-trader effect.

The dynamic patterns of bubbles in the inflow treatments depend on the proportion of new traders in the market. In the "Inflow $2 / 3$ " treatment, the new-trader effect dominates the market dynamics and price bubbles are less alleviated than those in the "Inflow $1 / 3$ " treatment. In the "Inflow $1 / 3$ " treatment, the variances of price bubbles among sessions are higher than those in the "Inflow $2 / 3$ " treatment. This higher variance suggests a more tight balance between the learning effect and the new-trader effect. In some sessions, the learning effect is more salient and leads to smaller bubbles, while in others the new-trader effect plays a more important role and generates lager bubbles.

We also compare the results from our baseline treatment, where a call market is used to clear the trading and $1 / 3$ of experienced traders are replaced by inexperienced traders in the fourth market, with the " $1 / 3$ inexperienced" treatment in DLM which uses a double auction in trading. We find that different market mechanisms have no significant impact on most bubble measures and thus the conclusions. However, the trading volume from the double auction is much larger than that from the call market, which is very reasonable because the double auction mechanism allows one single asset to be continuously traded for many times. Surprisingly or not, the prices and bubble measures generated by the two mechanisms are very similar, except those measures normalized by the trading volume.

Our findings are complement to those in Hussam, Porter and Smith (2008) who show that bubble can be rekindled with experienced subjects when imposing a large increase in liquidity and dividend uncertainty that greatly shock the environment of experienced subjects. Hence, experience is not robust to major new environment changes in determining the characteristics of a price bubble. We show that the effect of experience on bubbles also depends on the flow of new investors. 
A recent paper by Deck, Porter and Smith (2011) also investigates the impact of the entry and exit of investors on price bubbles. They introduce three overlapped generations in a 25-period market and the market cycles through five-period sequences of single generation trading and two generations trading. Because the liquidity increase and decrease along with the entry and exit of a generation, the market generates an $\mathrm{M}$ shaped double bubble price path. Their design is very different from ours in terms of the inflow of new traders. In our experiments, the initial endowment of money and assets is same at the beginning of each market, so the liquidity does not change with the inflow of new traders. Therefore, the pattern of price bubbles, found different from the previous studies, is purely due to the particular composition of experienced and inexperienced traders with the inflow of new traders.

The interpretation of our findings relates to the paper by Kirchler, Huber, and Stöckl (2011), who find that the declining fundamental value of the experimental assets confuses subjects and leads to the high mispricing and overvaluation. Based on their results, the effect of common group experience in alleviating bubbles might come from the reduced confusion about the fundamental value process. Our findings imply that a market with more confused/new traders is more likely to have bubbles. The existence of new and experienced traders can work together with confusion and/or heterogenous beliefs to sustain bubbles, as suggested by other studies (Hong, Harrison, and Jeremy C. Stein, 1999; Bloomfield, Robert, Maureen O'Hara, and Gideon Saar, 2009; Palfrey and Wang, 2011).

Our findings about the role of new traders in the formation of price bubbles have very important empirical relevance. First of all, the inflow of new traders is a salient feature when a new asset or financial product is introduced into the market or when there is a big shock to the market environment. Furthermore, bubbles are also more likely to occur in such occasions because the introduction of new financial products and new changes in the market environment, together with the inflow of new traders, can create large differences in price expectation and thus are more likely to generate price bubbles. Many historic bubbles, such as the South Sea bubble and the Dot-Com bubble, and the recently crashed housing bubble arise from a seemingly new environment or a market with dramatic financial creation. Lastly, the financial markets in emerging economy are becoming more important in the international financial market. New traders might play a crucial role in understanding some phenomena in those markets, for example, the Chinese warrant bubble documented by Xiong and Yu (2011).

\section{Experimental Design and Procedures}

The parameters in our experimental asset markets follow DLM, which has the closest research objective as ours. An asset's life span is ten periods. In each period, it pays a dividend of 0 or 20 francs, with equal probability. Trade takes place in each period, before dividends are determined. The dividend process determines the fundamental asset values, which equals the expected dividend in each period, 10 francs, times the number of dividend draws remaining.

A session involved four consecutive markets. Each market involved six traders, who could both buy and sell assets. Each of the six participants possessed an initial endowment of cash and units of the asset at the beginning of period 1 in each of the four markets. Before a market opened, half of the traders each started with a cash endowment of 200 francs and six assets, while each of the other

traders started with 600 francs and two assets. The participants received a table at the beginning of the experiment, describing the expected value of the asset's dividend stream at the beginning of each 
period. An individual's initial cash balance and asset inventory at the beginning of period 1 was the same in each market, and the inventory and balances held at the end of period 10 disappeared after the period dividend was paid and total earnings for that market were calculated. However, within each market, individual inventories of asset and cash balances carried over from one period to the next. The exchange rate was 100 francs to 1 Canadian dollar.

We had three treatments: two Inflow treatments-Inflow $1 / 3$ and Inflow $2 / 3$-and the Baseline treatment. In the "Inflow $1 / 3$ " treatment, 12 subjects were recruited and participated in the training period. After the training period, 8 subjects whose computer ID was between 5 to 12 were asked to go to the waiting room and would only participate in one of the four markets, while the other 4 subjects whose computer ID is between 1 to 4 were selected to participate in all the four markets. At the beginning of each market, two of the 8 subjects in the waiting room were randomly selected to enter the market. They were replaced by another two inexperienced traders when the market ended. When those subjects were in the waiting room, they were asked to complete as many cross-word puzzles and Sudoku puzzles as possible. They did not make any earnings by doing the puzzles, so that we control the income of the inexperienced traders when they enter the market. They were given an additional fixed payment of 15 dollars for compensation of time. The "Inflow $2 / 3$ " treatment is similar to the "Inflow 1/3" treatment, except that 18 subjects were recruited, subject 1 and 2 participated in all the four markets and the other 16 subjects participated in only one of the four markets. The baseline treatment is similar to the one-third treatment in DLM. There are 8 subjects in total for each session. In the fourth market, two experienced subjects who had participated in the first three markets were replaced by two new inexperienced subjects. Importantly, in all the treatments when new traders entered a new market, the initial cash endowment and units of assets for them is associated with the computer number, and is the same as that for the inexperieced traders in the previous markets. Therefore, in our design, the liquidity does not change with the inflow/outflow of traders.

Different from DLM, we used a call market (as in for example Friedman, 1993; Van Boening et al., 1993; Cason and Friedman, 1997) instead of a double auction market. The market was implemented by the z-Tree software (Fischbacher, 2007). ${ }^{2}$ In a call market, all bids and asks for a period are submitted simultaneously, aggregated into the market demand and supply curves, and the market is cleared at a uniform price for all transactions of that period. ${ }^{3}$ The adoption of a call market design allows us to compare our results with those in DLM and test whether the conclusion of DLM is robust to the market format.

In each period, each participant had an opportunity to submit one buy order and one sell order to the market. An individual's submitted buy order consisted of only one price and a maximum quantity the individual was willing to purchase at that price. Similarly, his sell order consisted of only one price and a maximum quantity the individual offered to sell at that price. Individuals did not observe any other agent's orders for the period when submitting their own orders. After all of the participants submitted their decisions, the computer calculated the market price, the lowest equilibrium price in

\footnotetext{
${ }^{2}$ We modified the z-Tree program posted by Haruvy et al. We are grateful for their generous share of the z-tree program.

${ }^{3}$ See Sunder (1995) for more detailed discussion of the advantages and disadvantages of call market versus continuous double auction design.
} 
the intersection of the market demand and supply curves constructed from the individual buy and sell orders. Participants who submitted buy orders at prices above the market price made purchases, and those who submitted sell orders at prices below the market price made sales. Any ties for last accepted buy or sell order were broken randomly. Participants were not permitted to sell short or to borrow funds.

The information provided to each individual at the end of each period consisted of the market price, the dividend, the number of units of asset he acquired and sold, his current inventory of the asset, the cash he received from sales and spent on purchases, his current cash balance, and the cumulative earnings for the session. For inexperienced subjects, the cumulative earnings for the session is the total earnings from the market that they participate in. Before subjects submit their buy and sell orders, the computer screen displayed the previous price history the subject had experienced. For experienced subjects, prices from all previous periods in all markets were displayed. For inexperienced subjects, only prices from all previous periods in the market they participated in were displayed.

The experiment took place in the Bell economic experimental lab in CIRANO in Montreal between May to July 2011. Subjects are undergraduate students from the universities in the Montreal area. No subjects had prior experience in similar experiments and all subjects participated in only one session. All sessions lasted less than 2.5 hours, including the first 45 minutes during which the experimenter read the instructions and trained the participants in the use of the market software. At the end of the experiment, participants were privately paid, in cash, the amount of their final cash holdings from all markets they had participated in, in addition to the show-up fee of $\$ 5$. All inexperienced traders were paid an additional fixed payment of $\$ 15 .^{4}$

\section{Results}

The difference between the inflow and baseline treatments lies in the introduction of a steady inflow of new traders over four repetitions of the same market. The inflow design leads to a different composition of experienced and inexperienced traders: in the inflow treatments, experienced traders are always interacting with different new traders; in the baseline treatment, experience comes from the interaction with the same group of traders in the first three markets. Consequently, the relative importance of the learning effect and the new-trader effect might be different in the inflow and baseline treatments.

Except the inflow of new traders, there are also subtle difference in information and learning. For information, the experienced traders in the Inflow treatments always have an asymmetric information advantage over the inexperienced traders, such as on the trading prices in previous markets; but in the baseline treatment, this kind of advantage only exists in the last market, although traders in all treatment have common knowledge of their market environments. Moreover, the experience in the baseline treatment is common group experience, but in the inflow treatments, it is dynamic group experience. The effects of the different experience might affect price bubbles differently too.(Is it the same argument as last paragraph?)

We expect that, price bubbles in the inflow treatments have less changes over the repetition of

\footnotetext{
${ }^{4}$ Although some inexperienced traders waited for a longer time and others waited for a shorter time, we choose to pay them the same amount in order to control the wealth when they enter the market.
} 
the market, comparing to those in the baseline treatment; in other words, bubbles are not or less substantially abated. Our conjecture is mainly based on the "new-trader effect", that is, the composite impact generated from the continuous entry of new traders. Overall, a steady inflow of new traders naturally makes each repetition of the market close to a new market and reduces the existence of experience and its effect on price bubbles. The more new traders the market has, the less effective the experience is. At the same time, in the market with continuous inflow of new traders, the experienced traders may learn less about the market and the pricing pattern, since the market has more uncertainty and is less predictable. Furthermore, if there is leaning, the experienced traders might attempt to take advantage of the inexperienced ones by maintaining certain level of price bubbles. However, as Sutter, Huber and Kirchler (2011) demonstrate, the existence of asymmetric information might alleviate price bubbles because of the strategic behavior of traders. (not quite understand)

Previous studies indicate that the thrice repeated market is enough to alleviate bubble, so we first investigate whether it is true for both baseline and inflow treatment. Our first hypothesis compares the measures of price bubbles in the first and the third market. The null hypothesis is that bubble measures in market 1 and market 3 are similar; the alternative hypothesis is that the magnitude of bubbles is smaller in market 3, when traders gain experience. We expect that the null hypothesis will be more likely to be supported in the inflow treatments, but the baseline treatment will be more in favor of the alternative hypothesis. Moreover, if we introduce more new traders after each repetition, we expect that bubbles are less abated.

Our second hypothesis then compares the magnitude of bubbles in market 3 and market 4 . In both baseline and inflow treatment, new inexperienced traders enter the fourth market. DLM have shown that introducing new traders in the last market will not cause the bubble-crash phenomenon to return. Following DLM, we expect no differences between market 3 and market 4 for the Baseline treatment, with the alternative hypothesis that the magnitude of bubbles is larger in market 4 . For the inflow treatment, we expect every market is more or less similar to market 1 , so we also expect no differences between market 3 and market 4, with the alternative hypothesis that the magnitude of bubbles is larger in market 3 since the experienced traders gain more experiences when staying longer in the market.

In the following sections, we first show the observed dynamics of asset prices and measure the extent of price bubbles-the deviation of prices from fundamental values. Based on the bubble measures, we quantify and test statistically the differences in bubbles across the repetition of the markets. We then investigate the interaction of the learning effect and the new-trader effect in sustaining or abating bubbles. Lastly, we compare the results from our baseline treatment with those from DLM.

\subsection{Summary Statistics}

Figure 1 describes the prices in each period averaged over all sessions, along with the fundamental values of the asset in the same period. First, price bubbles in both inflow treatments are less alleviated across the repeatedly operated asset markets, comparing to those in the baseline treatment. This observation supports our null hypothesis. Second, the average prices in the inflow $2 / 3$ treatment are lower than those in the inflow $1 / 3$ treatment and are more under-valued. This observation is related

to the continuous inflow of a relatively large proportion of new traders, since prices are more likely to 
be under-valued in a market with more new traders, as some previous studies have found. In order to provide more rigorous analysis, we will use the standard bubble measures to conduct quantitative assessment and statistical tests on the differences in price bubbles from different markets in different treatments. $^{5}$
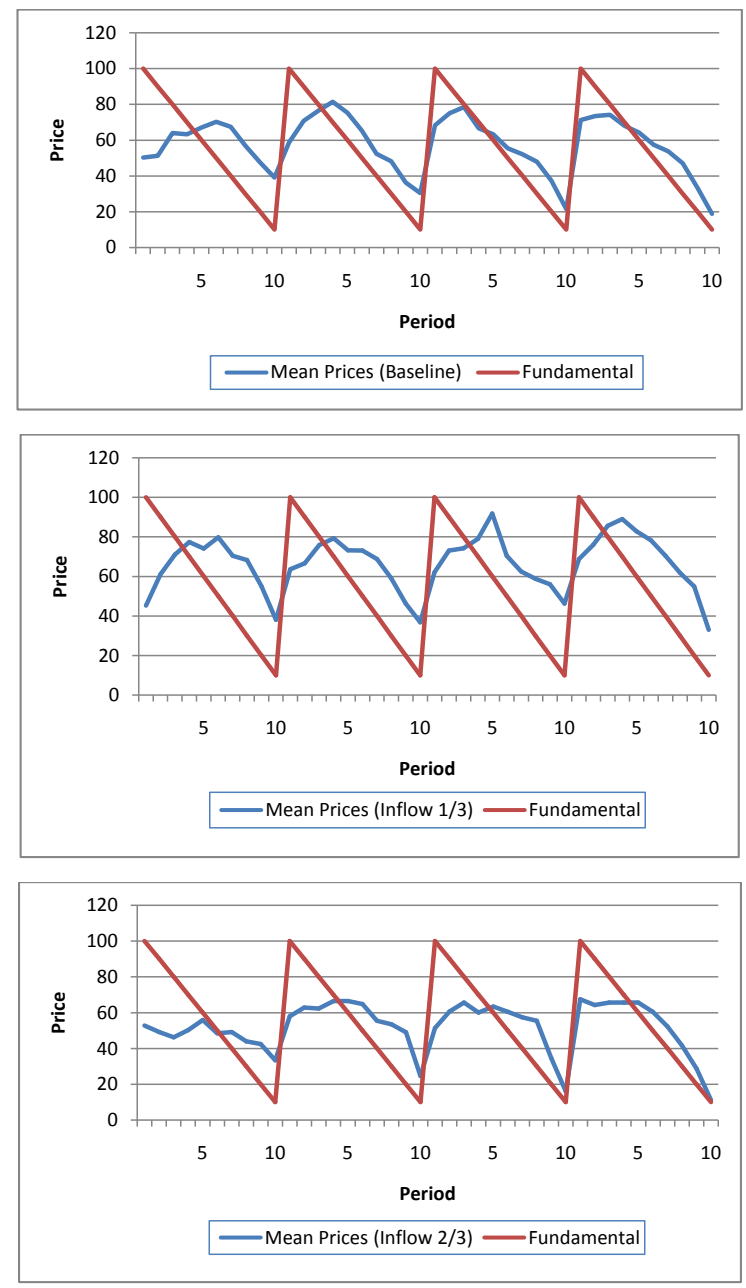

Figure 1: Observed Mean Prices and Fundamental Values

Following the literature (King et al. (1993), Van Boening et al. (1993), Porter and Smith (1995), Noussair and Tucker (2003) and Dufwenberg et al. (2005)), we use the following measurements to capture the extent of price bubbles.

- The Normalized Absolute Price Deviation: the sum, over all transactions, of the absolute deviations of prices from the fundamental value across the ten periods, normalized by the total

\footnotetext{
${ }^{5}$ In Figure 3-5 in Appendix B, we also show that the transaction price in each period of each market in each session, along with the fundamental value, respectively for each treatment. The pricing patterns are similar to those seen from Figure 1.
} 
number of shares outstanding. It equals

$$
\left(\sum_{t} q_{t}\left|p_{t}-f_{t}\right|\right) /(100 * T S U),
$$

where $q_{t}$ is the number of transactions in period $t$ and the total stock of units $T S U=24$ is the sum of all traders' inventories of asset. ${ }^{6}$

- The Normalized Average Price Deviation: the sum of the absolute deviation between the transaction price and the fundamental value across the ten periods, normalized by the total number of shares outstanding. ${ }^{7}$ It equals

$$
\left(\sum_{t}\left|p_{t}-f_{t}\right|\right) /(100 * T S U) .
$$

- The Price Amplitude: the difference between the maximum and minimum mean price deviations from fundamental value across the ten periods, normalized by the initial fundamental value. It equals

$$
\frac{\max _{t}\left\{p_{t}-f_{t}\right\}-\min _{t}\left\{p_{t}-f_{t}\right\}}{f_{1}}, \quad t=1,2, \ldots, 10,
$$

where $p_{t}$ and $f_{t}$ equal the average transaction price and the fundamental value in period $t$, respectively (in our experiment $f_{1}=100$. ) $^{8}$

- The Turnover: the volume of trades divided by the total number of outstanding assets. It equals

$$
\sum_{t} q_{t} / T S U
$$

Table 1 presents the mean and standard deviation of bubble measures for the four markets in each treatment, where the calculation is based on the prices from all sessions of each treatment. Previous studies have documented that the effect of experience on prices appears significantly by the third repetition of the market, so our focus is to compare the measures for market 1 and market 3 . Similar as seen from Figure 1, bubble measures are substantially abated in the baseline treatment; but they are less abated in the inflow treatments, and some measures even increase in the inflow $2 / 3$ treatment. Also, most of the bubble measures in the inflow $2 / 3$ treatment are smaller than those in the inflow $1 / 3$ treatment.

Another salient feature is that the between-session variances (standard deviations) of the bubble measures in the "Inflow $1 / 3$ " treatment are much larger than those in both baseline and "Inflow $2 / 3$ "

\footnotetext{
${ }^{6}$ We divide by $100^{*}$ TSU while some other studies simply divide by TSU to calculate Normalized Absolute Deviation and Turnover. The purpose is to make our measure comparable to previous studies. Previous studies calculated the normalized deviation in terms of dollars (units of 100 cents). Our prices and fundamental values are in terms of frans (cents). Therefore, the appropriate measure for comparison with previous studies would be in units of 100 francs.

${ }^{7}$ This definition is similar to the Total Dispersion in Haruvy et al. (2007), which is defined as $\sum_{t}\left|p_{t}-f_{t}\right|$. The above Normalized Average Price Deviation measure is also similar to the Relative Absolute Deviation (RAD) in Stock et al. (2010), which is normalized by the total periods and average fundamental value.

${ }^{8}$ In Haruvy et al. (2007), it is defined as $\left(\max _{t}\left\{p_{t}-f_{t}\right\}-\min _{t}\left\{p_{t}-f_{t}\right\}\right) / f_{t}$. Using Haruvy et al.'s definition of Price Amplitude (denoted as Price Amplitude 2 in Table 3 and 4 in Appendix B) does not change our statistical result. This definition is also similar to the Relative Deviation (RD) in Stockl et al. (2010), but the Relative Deviation (RD) is further normalized by the average fundamental value.
} 
Table 1: Mean and Variance of Bubble Measures for Market 1-4 (Averaged over Sessions in Each Treatment)

\begin{tabular}{|c|c|c|c|c|c|c|}
\hline \multirow[b]{2}{*}{ Measure } & \multicolumn{3}{|c|}{ Market 1} & \multicolumn{3}{|c|}{ Market 2} \\
\hline & Baseline & Inflow $1 / 3$ & Inflow $2 / 3$ & Baseline & Inflow $1 / 3$ & Inflow $2 / 3$ \\
\hline $\begin{array}{c}\text { Normalized Absolute } \\
\text { Price Deviation }\end{array}$ & $\begin{array}{l}0.407 \\
(0.190)\end{array}$ & $\begin{array}{l}0.560 \\
(0.395)\end{array}$ & $\begin{array}{c}0.325 \\
(0.100)\end{array}$ & $\begin{array}{c}0.343 \\
(0.207)\end{array}$ & $\begin{array}{c}0.289 \\
(0.133)\end{array}$ & $\begin{array}{c}0.333 \\
(0.107)\end{array}$ \\
\hline $\begin{array}{l}\text { Normalized Average } \\
\text { Price Deviation }\end{array}$ & $\begin{array}{c}0.114 \\
(0.029)\end{array}$ & $\begin{array}{l}0.138 \\
(0.072)\end{array}$ & $\begin{array}{c}0.096 \\
(0.013)\end{array}$ & $\begin{array}{c}0.096 \\
(0.026)\end{array}$ & $\begin{array}{c}0.098 \\
(0.038)\end{array}$ & $\begin{array}{c}0.085 \\
(0.016)\end{array}$ \\
\hline $\begin{array}{c}\text { Price } \\
\text { Amplitude }\end{array}$ & $\begin{array}{c}0.928 \\
(0.198)\end{array}$ & $\begin{array}{c}1.028 \\
(0.352)\end{array}$ & $\begin{array}{c}0.726 \\
(0.148)\end{array}$ & $\begin{array}{c}0.814 \\
(0.224)\end{array}$ & $\begin{array}{c}0.754 \\
(0.182)\end{array}$ & $\begin{array}{c}0.710 \\
(0.101)\end{array}$ \\
\hline \multirow[t]{3}{*}{ Turnover } & $\begin{array}{c}1.467 \\
(0.495)\end{array}$ & $\begin{array}{c}1.475 \\
(0.568)\end{array}$ & $\begin{array}{c}1.325 \\
(0.283)\end{array}$ & $\begin{array}{c}1.142 \\
(0.478)\end{array}$ & $\begin{array}{r}1.092 \\
(0.340)\end{array}$ & $\begin{array}{c}1.292 \\
(0.230)\end{array}$ \\
\hline & \multicolumn{3}{|c|}{ Market 3} & \multicolumn{3}{|c|}{ Market 4} \\
\hline & Baseline & Inflow $1 / 3$ & Inflow $2 / 3$ & Baseline & Inflow $1 / 3$ & Inflow $2 / 3$ \\
\hline $\begin{array}{c}\text { Normalized Absolute } \\
\text { Price Deviation }\end{array}$ & $\begin{array}{c}0.202 \\
(0.125) \\
\end{array}$ & $\begin{array}{c}0.296 \\
(0.184) \\
\end{array}$ & $\begin{array}{c}0.329 \\
(0.151) \\
\end{array}$ & $\begin{array}{r}0.205 \\
(0.122) \\
\end{array}$ & $\begin{array}{r}0.321 \\
(0.408) \\
\end{array}$ & $\begin{array}{c}0.214 \\
(0.082)\end{array}$ \\
\hline $\begin{array}{l}\text { Normalized Average } \\
\text { Price Deviation }\end{array}$ & $\begin{array}{c}0.075 \\
(0.016)\end{array}$ & $\begin{array}{l}0.108 \\
(0.085)\end{array}$ & $\begin{array}{c}0.084 \\
(0.020)\end{array}$ & $\begin{array}{l}0.061 \\
(0.020)\end{array}$ & $\begin{array}{c}0.110 \\
(0.117)\end{array}$ & $\begin{array}{c}0.070 \\
(0.026)\end{array}$ \\
\hline $\begin{array}{c}\text { Price } \\
\text { Amplitude }\end{array}$ & $\begin{array}{c}0.700 \\
(0.099)\end{array}$ & $\begin{array}{c}0.848 \\
(0.552)\end{array}$ & $\begin{array}{c}0.748 \\
(0.197)\end{array}$ & $\begin{array}{c}0.494 \\
(0.208)\end{array}$ & $\begin{array}{c}0.790 \\
(0.776)\end{array}$ & $\begin{array}{c}0.544 \\
(0.086)\end{array}$ \\
\hline Turnover & $\begin{array}{c}1.083 \\
(0.320)\end{array}$ & $\begin{array}{c}1.125 \\
(0.355)\end{array}$ & $\begin{array}{c}1.317 \\
(0.398)\end{array}$ & $\begin{array}{l}1.067 \\
(0.395)\end{array}$ & $\begin{array}{c}1.000 \\
(0.355)\end{array}$ & $\begin{array}{c}1.275 \\
(0.253)\end{array}$ \\
\hline
\end{tabular}

treatments. This might reflect the relative weight of the learning effect and the new-trader effect in determining trading behavior and prices. When these two effects have a tight balance and neither of them can dominate the market, as in the "Inflow 1/3" treatment, we might see higher variances in price bubbles across different sessions. On the opposite, in the baseline and the inflow $1 / 3$ treatments, the market structures are more stable in the sense that either new-traders or experienced traders dominates the markets, so the pricing presents a relatively more uniform pattern.

Overall, the summary statistics show that learning of experienced traders seems to have the largest impact on bubble alleviation in the baseline treatment, where learning comes from the interaction with a fixed group of traders. For the inflow treatments, when the market has more inexperienced traders, such as in the inflow $2 / 3$ treatment, the new-trader effect is dominating; when the market has more experienced traders, such as in the inflow $1 / 3$ treatment, the learning effect of experienced traders and the new-trader effect work together in sustaining asset bubbles.

\subsection{Statistical Tests on Bubbles Alleviation across Markets}

In this section we report the Permutation tests on how price bubbles change across the sequence of the markets. Our focus is to test Hypothesis one and two, that is, the bubble measures are not significantly different between market 1 and market 3 and between market 3 and market 4 . Table 2 gives the $p$-values from the Permutation tests for all bubble measures.

In the baseline treatment, most of the tests reject the null hypothesis that $M_{1}=M_{3}$ at $5 \%$ significance level. The only exception is the test using Turnover, which rejects the null hypothesis at $6 \%$ 
Table 2: $p$-value of Permutation Tests

\begin{tabular}{|c|c|c|c|c|c|c|c|c|c|}
\hline \multirow[b]{2}{*}{ Measure } & \multicolumn{3}{|c|}{$M_{1}=M_{3}$} & \multicolumn{3}{|c|}{$M_{1}=M_{4}$} & \multicolumn{3}{|c|}{$M_{3}=M_{4}$} \\
\hline & $\mathrm{BL}$ & IF $1 / 3$ & IF $2 / 3$ & $\mathrm{BL}$ & IF $1 / 3$ & IF $2 / 3$ & $\mathrm{BL}$ & IF $1 / 3$ & IF $2 / 3$ \\
\hline $\begin{array}{c}\text { Normalized Absolute } \\
\text { Price Deviation }\end{array}$ & 0.031 & 0.094 & 0.531 & 0.031 & 0.031 & 0.094 & 0.438 & 0.563 & 0.219 \\
\hline $\begin{array}{l}\text { Normalized Average } \\
\text { Price Deviation }\end{array}$ & 0.031 & 0.063 & 0.219 & 0.031 & 0.156 & 0.063 & 0.938 & 0.531 & 0.219 \\
\hline $\begin{array}{c}\text { Price } \\
\text { Amplitude }\end{array}$ & 0.031 & 0.156 & 0.656 & 0.031 & 0.188 & 0.094 & 0.969 & 0.313 & 0.094 \\
\hline Turnover & 0.063 & 0.188 & 0.500 & 0.031 & 0.063 & 0.438 & 0.563 & 0.313 & 0.406 \\
\hline
\end{tabular}

significance level. These results provide strong evidence that asset bubbles are alleviated substantially when traders gain enough common group experience, by the third repetition of the markets.

On the contrary, bubbles in the inflow treatments are not alleviated substantially from market 1 to market 3 . In both Inflow $1 / 3$ and Inflow $2 / 3$ treatments, none of the tests using different measures can reject the null hypothesis at $5 \%$ significance level. Only the Normalized Absolute Price Deviation and the Normalized Average Price Deviation in the Inflow 1/3 treatment can reject the null hypothesis at $10 \%$ significance level. Hence, these tests overall do not suggest there is a significant change in price bubbles from market 1 to market 3 .

For all treatments, there are no statistical differences in price bubbles between market 3 and market 4 (except that Price Amplitude is marginally different at $10 \%$ significance level in "Inflow $2 / 3$ " treatment). The result for the baseline treatment suggests the same finding as in DLM: after traders earn enough experience (thrice-experienced), the introduction of new traders will not cause the bubbles to return.

Comparing the "Inflow $1 / 3$ " and "Inflow $2 / 3$ " treatments, the no-alleviation result in price bubbles $\left(M_{1}=M_{3}\right)$ is more salient in the "Inflow $2 / 3$ " treatment, according to the level of the statistical significance. This suggests that more new traders in the market help sustain bubble. However, the no-difference tests between market 3 and market 4 have lower significant level in the "Inflow $2 / 3$ " treatment than in the "Inflow $1 / 3$ " treatment, especially for the price amplitude. These two findings suggest that the experienced traders in the "Inflow $2 / 3$ " treatment need more repetition to learn about the market.

When we compare the testing results for market 1 and market 4 , the markets in the inflow treatments seem more efficient, although statitistically there are no significant difference. This suggests that it might take more time to make experience has effect on price bubbles, when there is a steady inflow of new traders.

We also did the tests on the differences between other markets, such as market 2, 3 and 4 . We still find strong evidences supporting that bubbles are significantly abated in the baseline treatment, but not in the inflow treatments. For instance, the tests using Normalized Average Price Deviation and Price Amplitude show that price bubbles are significantly alleviated from market 2 to market 3, and from market 2 to market 4 ; but not for the inflow treatments. The test using Turnover shows that there is more turnover across the markets in the baseline treatment, but no difference in the Inflow treatments. The test using Normalized Absolute Price Deviation only shows differences from market 1 to market 
4 in the baseline treatments, but not in the inflow treatments. ${ }^{9}$

\subsection{Experienced and Inexperienced Traders}

In understanding the systematic differences in price bubbles between the baseline and the inflow treatments, the role of experiences are crucial. So in this section we investigate the payoffs and the trading behavior of experienced and inexperienced traders.

As seen from Figure 2, the comparison on earnings between the experienced and inexperienced traders shows that the average earnings of experienced traders are systematically higher than those of inexperienced traders, except in the first market. ${ }^{10}$ This finding supports that learning and experience play a role in the experimental asset market. However, such role seems most important in the baseline treatment. In the inflow treatments, some of the statistical tests on the differences in earnings of experienced and inexperienced traders are not significant.

In "Inflow $1 / 3$ " treatment, the trading volume is higher for experienced traders than inexperienced traders. For other treatments, the trading volumes among experienced and inexperienced traders have no clear difference, which might be related to the market mechanism we are using. In the call market, the total trade volume is much smaller than in the double auction market, so there is much smaller room to generate differences in trading volume for experienced and inexperienced traders.

\subsection{Impact of Market Mechanisms}

One question of our interest is how the market institution affects the pricing bubble, given the same market parameters. Using Robust Rank Order test, we compare our Baseline treatment with the corresponding $1 / 3$ inexperienced-trader treatment in DLM. We find that Normalized Average Price Deviation and Price Amplitude is not significantly different between these two treatments. However, the Turnover is $1 \%$ significantly higher in DLM than in our Baseline treatment (actually the measure of Turnover in any session in DLM is higher than in any session in our Baseline treatment), which suggests that the double auction market produces a much higher level of trade transaction. The average Turnover in our Baseline is 1.19, as contrast to 4.64 in DLM. Haruvy et al. has the average Turnover 1.73, which is still higher than ours but much closer. The difference in Turnover also leads to a significant difference in Normalized Absolute Price Deviation $(p<0.5$ one-tailed Robust Rank Order test). This comparison implies that the findings in DLM are robust to the change of market mechanism.

\footnotetext{
${ }^{9}$ For the between-subject comparison, we did the robust rank order tests on the difference in price bubbles for the same markets from different treatments and find no significant difference. The intuition is that bubble measures in the inflow treatment on average are bigger but also have higher variance than those in the baseline treatment, so the rankbased robust order tests cannot distinguish such differences. We suspect that, if we adopt a market parameterization with more traders, more trading periods and more uncertainty on the dividends, the differences between treatments may become more significant.

${ }^{10}$ For the first three markets, the calculation uses data from the inflow treatments. For the fourth market, we use all the treatments. The average earnings is for each person, not the average at the session level.
} 

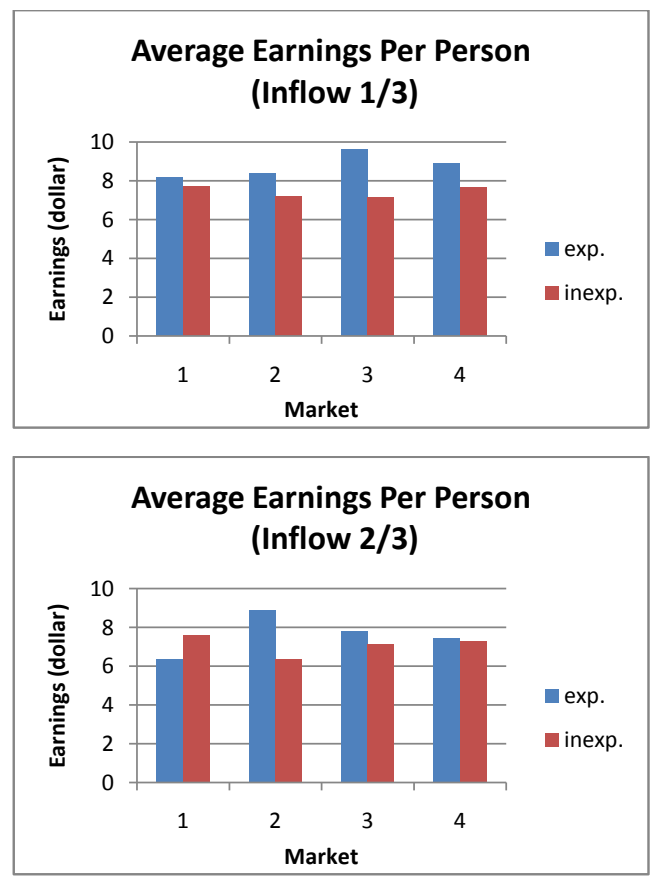

Figure 2: Average Earnings of Experienced and Inexperienced Traders (Inflow Treatment)

\section{Conclusions}

Using an experimental design with a steady inflow of new investors in a sequence of experimental asset markets, we find that bubble sustains and has a significantly different trend, comparing to the design that only introduces new investors in the last asset market. We demonstrate that the inflow of new investors does play an important role in the formation and change of price bubbles. The new-trader effect work together with the learning effect in determining the market dynamics. The relative importance and interaction of these two effects depend on the composition of experienced and inexperienced traders in the asset market.

The experimental literature on price bubbles has the robust finding that experience has a strong effect in alleviating bubbles in a stationary environment and such effect can dominate the impact of inexperienced traders in a setting with even a small fraction of experienced traders. However, experience alone is not a sufficient condition to eliminate bubbles, as shown in Hussam, Porter, and Smith (2008). We compliment to this strand of literature by showing that when there is a continuous inflow of new traders, the role of experience could be more complicated.

This paper provides some cues on the contrasting findings from the experimental and empirical studies, related to the importance of experience and learning in the formation of price bubbles. It is possible that learning might not have effect on price bubbles when there is a steady inflow of new traders, which is very likely to be the case in Xiong and Yu (2011), as Pan and Shi (2011) show that, 
using data from the same market as Xiong and $\mathrm{Yu}$, the entries of new investors help sustain asset price bubbles.

The importance of new traders and their interaction with experienced traders echos those empircal findings in Greenwood and Nagel (2009) and Seru, Stoffman and Shumway (2010). Considering the larger innovation of financial products and the rapid development of emerging markets, new taders might play even a bigger role in asset pricing and the formation of price bubbles.

Further studies could investigate the role of the inflow of new traders in price bubble formation by incoporating other factors that are essential elements in asset pricing, such as information, beliefs, and heterogeneity of investors. For example, Sutter, Huber and Kirchler (2011) introduce asymmetric information into the market and find that it alleviate price bubbles. The different information of traders essentially leads to different composition of investors, which has some similarity to our design but they find that asymmetric information reduces bubbles. It might be interesting to show how information could play a role when there is a steady inflow of new traders. 


\section{References}

[1] Bloomfield, Robert, Maureen O'Hara, and Gideon Saar, 2009. "How Noise Trading Affects Markets: An Experimental Analysis." Review of Financial Studies, 22(6): 2275- 2302.

[2] Deck, Cary, David Porter, and Vernon Smith, 2011. "Double Bubbles in Assets Markets with Multiple Generations." Working paper.

[3] Dufwenberg, Martin, Tobias Lindqvist, and Evan Moore. 2005. "Bubbles and Experience: An Experiment." American Economic Review, 95(5): 1731-37.

[4] Greenwood, Robin and Stefan Nagel, 2009. Inexperienced Investors and Bubbles. Journal of Financial Economics 93:239-58.

[5] Haruvy, Ernan, YaronLahav, and Charles Noussair, 2007, Traders' expectations in asset markets: experimental evidence, American Economic Review, 97, 1901-1920.

[6] Haruvy, Ernan, and Charles N. Noussair. 2006. "The effect of short selling on bubbles and crashes in experimental spot asset markets." The Journal of Finance, 61(3): 1119-1157.

[7] Hong, Harrison, and Jeremy C. Stein. 1999. "A Unified Theory of Underreaction, Momentum Trading, and Overreaction in Asset Markets." Journal of Finance, 54(6): 2143-2184.

[8] Hussam, Reshmaan, David Porter, and Vernon Smith, 2008, Thar she blows: Can bubbles be rekindled with experienced subjects? American Economic Review,98, 924-937.

[9] Kirchler, M., Huber, J., Stöckl, T. (2011), Thar she bursts-Reducing confusion reduces bubbles. American Economic Review (forthcoming).

[10] King, Ronald R., Smith, Vernon L., Williams, Arlington W. and Van Boening, Mark V. "The Robustness of Bubbles and Crashes in Experimental Stock Markets," in Richard H. Day and Ping Chen, eds., Nonlinear dynamics and evolutionary economics. Oxford: Oxford University Press, 1993, pp. 183-200.

[11] Lei, Vivian, Charles N. Noussair, and Charles R. Plott. 2001. "Nonspeculative Bubbles in Experimental Asset Markets: Lack of Common Knowledge of Rationality vs. Actual Irrationality." Econometrica, 69(4): 831-59.

[12] Noussair, Charles N. and Tucker, Steven. "Futures Markets and Bubble Formation in Experimental Asset Markets." Pacific Economic Review, 2006, 11(2), pp. 167-184.

[13] Porter, David P. and Smith, Vernon L. "Futures Contracting and Dividend Uncertainty in Experimental Asset Markets." Journal of Business, 1995, 68(4), pp. 509-41.

[14] Palfrey, Thomas R. and Stephanie W. Wang. 2011. "Speculative Overpricing in Asset Markets with Information Flows", working paper.

[15] Pan, Deng and Shi Donghui. 2011. "New Investors and Bubbles: An Analysis of the Baosteel Call Warrant Bubble." Fudan University, Woking Paper. 
[16] Seru, Amit, Noah Stoffman and Tyler Shumway, "Learning By Trading." Review of Financial Studies, 23(2), 2010, 705-739.

[17] Smith, Vernon L., Gerry L. Suchanek, and Arlington W. Williams.1988. "Bubbles, Crashes, and Endogenous Expectations in Experimental Spot Asset Markets." Econometrica, 56(5): 111 9-51.

[18] Smith, Vernon, Mark van Boening, and Charissa P. Wellford. 2000. "Dividend timing and behavior in laboratory asset markets." Economic Theory, 16: 567-583.

[19] Stöckl Thomas, J. Huber, and Michael Kirchler. 2010. "Bubble measures in experimental asset markets." Experimental Economics, 13: 284-298.

[20] Sunder, Shyam. 1995. "Experimental Asset Markets: A Survey." In Handbook of Experimental Economics, ed. John H. Kagel and Alvin E. Roth, 445-500. Princeton: Princeton University Press.

[21] Sutter, M., Huber, J., Kirchler, M. 2011. "Bubbles and information: An experiment." Management Science, forthcoming.

[22] Xiong, Wei, and Jialin Yu. 2011. "The Chinese Warrants Bubble." American Economic Review 101, 2011, 2723-2753.

[23] Van Boening, Mark V.; Williams, Arlington W. and LaMaster, Shawn. "Price Bubbles and Crashes in Experimental Call Markets." Economics Letters, 1993, 41(2), pp. 179-85. 


\section{Appendix A: Instructions for experiment (Inflow treatment)}

\section{General Instructions}

This is an experiment in the economics of market decision making. The instructions are simple and if you follow them carefully and make good decisions, you might earn a considerable amount of money, which will be paid to you in cash at the end of the experiment. The experiment will consist of several sequences of 10 trading periods in which you will have the opportunity to buy and sell in a market. The currency used in the market is francs. All trading will be in terms of francs. The cash payment to you at the end of the experiment will be in dollars. The conversion rate is 100 francs to 1 dollar.

\section{How to Use the Computerized Market}

In each period, you will see a computer screen like the one shown below. You can use the interface to buy and sell Shares. At the top of your computer screen, in top left corner, you can see the Money and Shares you have available.

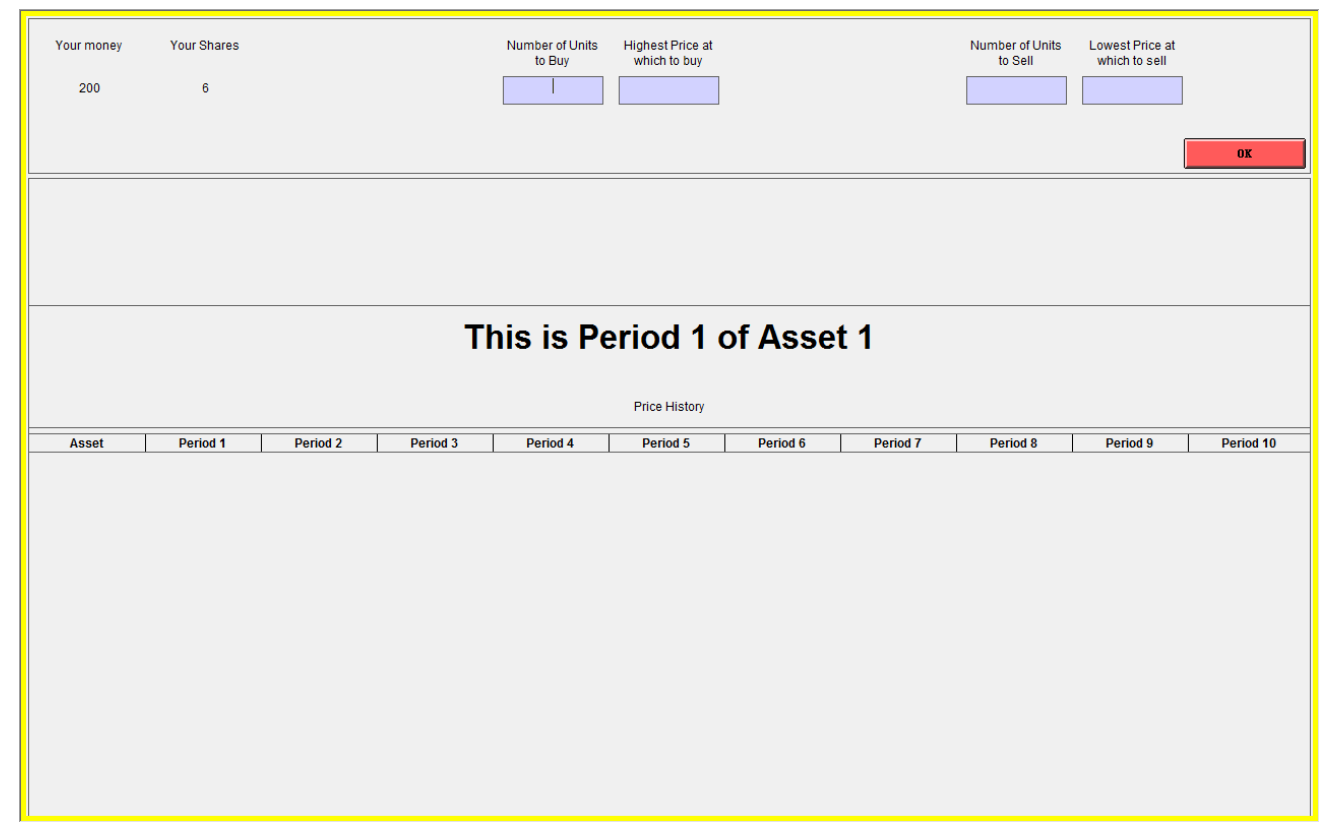

At the beginning of each trading period, if you wish to purchase shares you can send in a buy order. Your buy order indicates the number of shares you would like to buy and the highest price that you are willing to pay. Similarly, if you wish to sell shares, you can send in a sell order. Your sell order indicates the number of shares you are offering to sell and the lowest price that you are willing to accept. The price at which you offer to buy must be less than the price at which you offer to sell. The price you specify in your order is a per-unit price, at which you are offering to buy or sell each share. 
The computer program will organize the buy and sell orders and uses them to determine the trading price at which units are bought and sold. All transactions in a given period will occur at the same trading price. Generally, the number of shares with sell order prices at or below this clearing price is equal to the number of shares with buy order prices at or above this clearing price. The people who submit buy orders at prices above the trading price make purchases, and those who submit sell orders at prices below the trading price make sales.

Example of how the market works: Suppose there are four traders in the market and:

- Trader 1 submits an offer to buy at 60

- Trader 2 submits an offer to buy at 20

- Trader 3 submits an offer to sell at 10

- Trader 4 submits an offer to sell at 40

At any price above 40, there are more units offered for sale than for purchase. At any price below 20 there are more units offered for purchase than for sale. At any price between 21 and 39 there is an equal number of units offered for purchase and for sale. The trading price is the lowest price at which there is an equal number of units offered for purchase and for sale. In this example that price is 21 . Trader 1 makes a purchase from trader 3 at a price of 21 .

\section{Specific Instructions for This Experiment}

The experiment will consist of four independent sequences of 10 trading periods. In each sequence, there are 6 traders in the market. Before the start of the first sequence, four of you, whose computer number is between 1-4, will be selected to participate in all the four sequences. The other 8 individuals will only participate in one of the four sequences. If your computer number is between 5-12, you will be asked to go to the waiting room after the training period and will be randomly selected to participate in one of the four sequences. You will not be doing anything connected with this experiment when you stay in the waiting room.

At the beginning of the sequence, half of the 6 traders will have an endowment of 6 shares and 200 francs and the other half will be endowed with 2 shares and 600 francs.

In each period of a sequence, there will be a market open, operating under the rules described above, in which you are permitted to buy and sell shares. Shares have a life of 10 periods. Your shares carry over from one trading period to the next. For example, if you have 5 shares at the end of period 1, you will have 5 shares at the beginning of period 2 .

You receive dividends for each share in your inventory at the end of each of the 10 trading periods. At the end of each trading period, including period 10, each share you hold will pay you a dividend of 0 , or 20, each with equal chance. This means that the average dividend for each share in each period is 10 . The dividend is added to your money balance automatically after each period. After the dividend is paid at the end of period 10, the market ends and there are no further earnings possible from shares in the current market.

A new 10-period market will then begin, in which you can trade shares of a new asset for 10 periods. If you are selected to participate in all the four sequences, the amount of shares and 
money that you have at the beginning of the new market will be the same as at the beginning of the first 10-period market. There will be four 10-period markets making up the experiment.

\section{Average Holding Value Table}

You can use the AVERAGE HOLDING VALUE TABLE in front of you to help you make decisions. It tells you how much, on average, each share will pay you in dividends if you hold it from now until the end of the 10-period market.

The first column indicates the current period. The second column gives the average earnings from each unit that you keep in your inventory for the remainder of the 10-period market. It is calculated by multiplying the average dividend in each period, 10, by the number of periods remaining, including the current period.

\section{Price History}

In each period, when you send in a buy order and/or a sell order, you can observe your previous trading prices. If you are selected to participate in all the four sequences, you will observe all the previous trading prices formed in each period of each sequence. If you are selected to participate in one of the four sequences, you will observe all the previous trading prices formed in each period of the sequence that you participate in.

\section{Your Earnings}

Your earnings for a 10-period market will equal the total amount of cash that you have at the end of period 10, after the last dividend has been paid. It is calculated in the following way:

The money you have at the beginning of period 1

+ the dividends you receive

+ the money received from sales of shares

- the money spent on purchases of shares.

If you are selected to participate in all the four sequences, your earnings for the entire experiment will equal the total earnings from all the four sequences of the 10-period markets that make up the experiment, plus $\$ 5$ show-up fee.

If you are selected to participate in only one of the four sequences, your earnings for the entire experiment will equal the total earnings from the sequence that you have participated in, plus $\$ 15$ fixed payment, plus $\$ 5$ show-up fee. 


\section{AVERAGE HOLDING VALUE PER SHARE}

\begin{tabular}{|c|c|}
\hline $\begin{array}{c}\text { Current } \\
\text { Period }\end{array}$ & $\begin{array}{c}\text { Average Holding Value } \\
\text { Per Share }\end{array}$ \\
\hline 1 & 100 \\
\hline 2 & 90 \\
\hline 3 & 80 \\
\hline 4 & 70 \\
\hline 5 & 60 \\
\hline 6 & 50 \\
\hline 7 & 40 \\
\hline 8 & 30 \\
\hline 9 & 20 \\
\hline 10 & 10 \\
\hline
\end{tabular}




\section{Appendix B: Additional Figures and Tables}
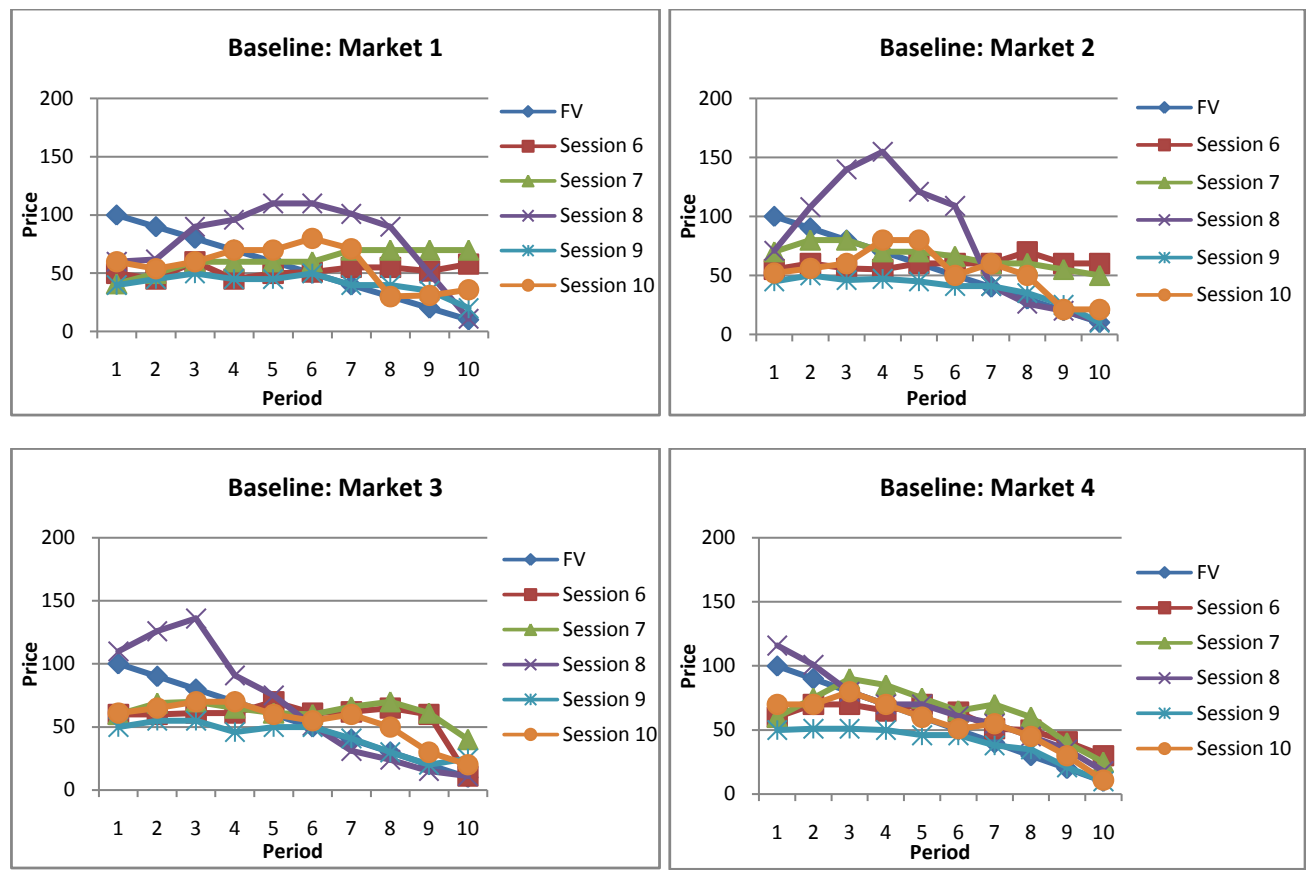

Figure 3: Transaction Price in Each Period, All Markets and Sessions in Baseline Treatment 

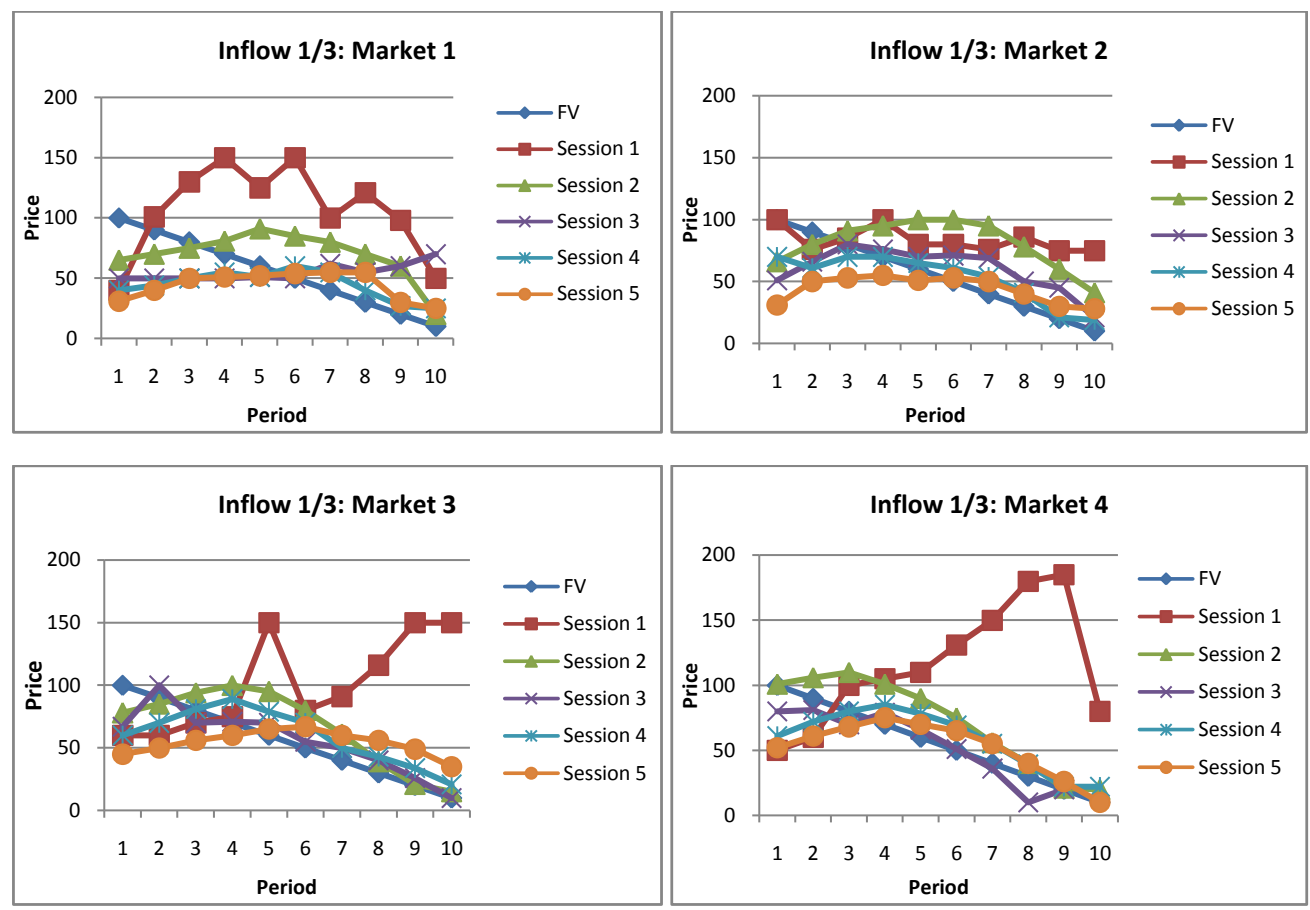

Figure 4: Transaction Price in Each Period, All Markets and Sessions in "Inflow 1/3" Treatment
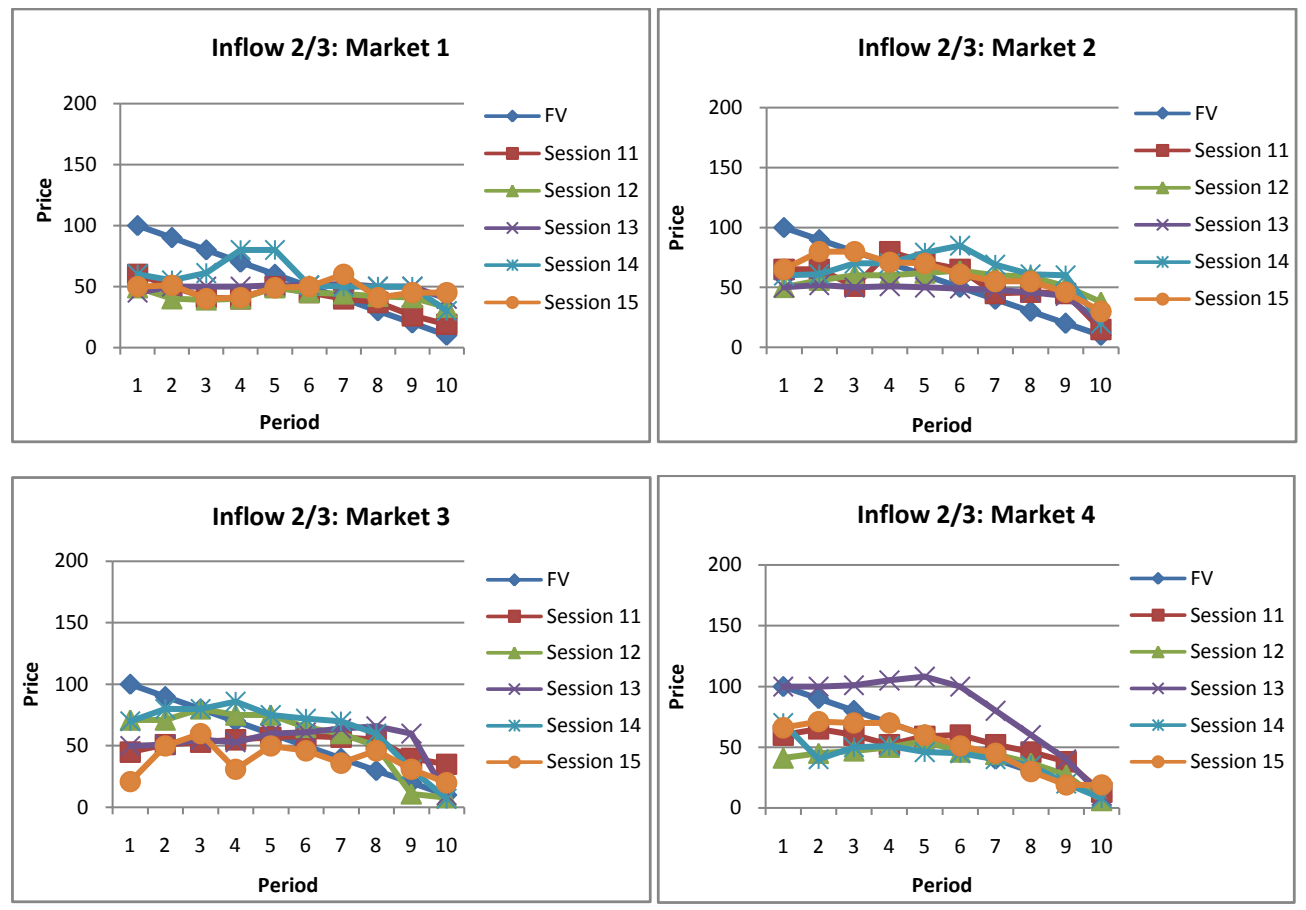

Figure 5: Transaction Price in Each Period, All Markets and Sessions in "Inflow 2/3" Treatment 
Table 3: Various Measures, By Market and Session, in Inflow Treatment

\begin{tabular}{|c|c|c|c|c|c|c|c|c|c|c|}
\hline \multicolumn{11}{|c|}{ Session } \\
\hline Market & I1 $/ 3 \_1$ & I1 $/ 3 \_2$ & $\mathrm{I} 1 / 3 \_3$ & I1 $/ 3 \_4$ & I1 $1 / 3 \_5$ & I2/3_1 & I $2 / 3 \_2$ & I2/3_3 & I2/3_4 & I2/3_5 \\
\hline \multicolumn{11}{|c|}{ Normalized absolute price deviation } \\
\hline 1 & 1.206 & 0.351 & 0.473 & 0.605 & 0.168 & 0.173 & 0.425 & 0.405 & 0.298 & 0.325 \\
\hline 2 & 0.391 & 0.351 & 0.226 & 0.083 & 0.393 & 0.180 & 0.336 & 0.360 & 0.478 & 0.310 \\
\hline 3 & 0.568 & 0.244 & 0.067 & 0.242 & 0.358 & 0.231 & 0.250 & 0.556 & 0.198 & 0.410 \\
\hline 4 & 1.048 & 0.150 & 0.102 & 0.197 & 0.109 & 0.313 & 0.249 & 0.199 & 0.222 & 0.088 \\
\hline \multicolumn{11}{|c|}{ Normalized average price deviation } \\
\hline 1 & 0.265 & 0.111 & 0.123 & 0.090 & 0.102 & 0.078 & 0.103 & 0.103 & 0.085 & 0.108 \\
\hline 2 & 0.130 & 0.143 & 0.081 & 0.050 & 0.088 & 0.073 & 0.099 & 0.085 & 0.101 & 0.064 \\
\hline 3 & 0.255 & 0.072 & 0.040 & 0.070 & 0.105 & 0.098 & 0.056 & 0.101 & 0.070 & 0.097 \\
\hline 4 & 0.317 & 0.071 & 0.037 & 0.061 & 0.063 & 0.068 & 0.078 & 0.106 & 0.065 & 0.033 \\
\hline \multicolumn{11}{|c|}{ Price amplitude } \\
\hline 1 & 1.60 & 0.75 & 1.10 & 0.75 & 0.94 & 0.490 & 0.740 & 0.850 & 0.700 & 0.850 \\
\hline 2 & 0.79 & 0.89 & 0.78 & 0.44 & 0.87 & 0.600 & 0.810 & 0.730 & 0.800 & 0.610 \\
\hline 3 & 1.80 & 0.57 & 0.43 & 0.60 & 0.84 & 0.800 & 0.490 & 0.900 & 0.600 & 0.950 \\
\hline 4 & 2.15 & 0.30 & 0.29 & 0.58 & 0.63 & 0.580 & 0.660 & 0.500 & 0.550 & 0.430 \\
\hline \multicolumn{11}{|c|}{ Price amplitude- 2} \\
\hline 1 & 4.600 & 2.350 & 6.500 & 2.100 & 2.190 & 1.388 & 2.856 & 3.550 & 2.400 & 4.000 \\
\hline 2 & 6.656 & 3.440 & 1.740 & 1.222 & 2.490 & 1.613 & 3.300 & 1.650 & 2.400 & 2.350 \\
\hline 3 & 14.400 & 0.820 & 0.663 & 1.500 & 3.050 & 3.050 & 1.117 & 2.500 & 1.300 & 1.790 \\
\hline 4 & 8.750 & 0.990 & 1.129 & 1.590 & 0.855 & 1.300 & 0.940 & 1.000 & 0.722 & 1.240 \\
\hline \multicolumn{11}{|c|}{ Turnover } \\
\hline 1 & 1.833 & 1.375 & 1.333 & 2.167 & 0.667 & 0.917 & 1.500 & 1.667 & 1.292 & 1.250 \\
\hline 2 & 1.208 & 0.833 & 1.000 & 0.792 & 1.625 & 1.000 & 1.125 & 1.375 & 1.583 & 1.375 \\
\hline 3 & 1.042 & 1.500 & 0.583 & 1.125 & 1.375 & 0.958 & 1.583 & 1.875 & 1.000 & 1.167 \\
\hline 4 & 1.250 & 0.792 & 0.708 & 1.500 & 0.750 & 1.625 & 0.958 & 1.292 & 1.375 & 1.125 \\
\hline
\end{tabular}


Table 4: Various Measures, By Market and Session, in Baseline Treatment

\begin{tabular}{cccccc}
\hline & \multicolumn{5}{c}{ Session } \\
\cline { 2 - 6 } Market & B1 & B2 & B3 & B4 & B5 \\
\hline \multicolumn{5}{c}{ Normalized absolute price deviation } \\
1 & 0.591 & 0.621 & 0.315 & 0.319 & 0.188 \\
2 & 0.663 & 0.365 & 0.283 & 0.313 & 0.090 \\
3 & 0.270 & 0.312 & 0.050 & 0.295 & 0.083 \\
4 & 0.220 & 0.371 & 0.081 & 0.260 & 0.091 \\
\multicolumn{5}{c}{ Normalized average price deviation } \\
1 & 0.113 & 0.133 & 0.153 & 0.088 & 0.085 \\
2 & 0.114 & 0.080 & 0.133 & 0.078 & 0.077 \\
3 & 0.090 & 0.093 & 0.067 & 0.067 & 0.058 \\
4 & 0.071 & 0.085 & 0.042 & 0.068 & 0.038 \\
\multicolumn{5}{c}{ Price amplitude } \\
1 & 0.98 & 1.19 & 1.01 & 0.75 & 0.71 \\
2 & 0.95 & 0.70 & 1.14 & 0.60 & 0.68 \\
3 & 0.80 & 0.81 & 0.65 & 0.65 & 0.59 \\
4 & 0.61 & 0.70 & 0.16 & 0.55 & 0.45 \\
\multicolumn{7}{c}{ Price amplitude-2 } \\
1 & 5.300 & 6.590 & 2.400 & 1.600 & 3.000 \\
2 & 5.450 & 4.300 & 1.504 & 0.800 & 1.580 \\
3 & 2.400 & 3.400 & 0.950 & 2.000 & 1.390 \\
4 & 2.400 & 1.900 & 0.800 & 0.667 & 0.800 \\
\multicolumn{7}{c}{ Turnover } \\
1 & 1.917 & 2.000 & 0.833 & 1.417 & 1.167 \\
2 & 1.708 & 1.500 & 0.583 & 1.167 & 0.750 \\
3 & 1.208 & 1.250 & 0.708 & 1.458 & 0.792 \\
4 & 1.208 & 1.667 & 0.625 & 0.875 & 0.958 \\
\hline \multicolumn{7}{c}{}
\end{tabular}


Table 5: Average Earnings by Experienced and Inexperienced Traders

(All Sessions and All Markets, in Dollar)

\begin{tabular}{|c|c|c|c|c|c|c|c|c|c|c|c|c|c|}
\hline & \multicolumn{3}{|c|}{ Market 1 } & \multicolumn{3}{|c|}{ Market 2 } & \multicolumn{3}{c|}{ Market 3 } & \multicolumn{3}{c|}{ Market 4 } \\
\cline { 2 - 15 } Session & exp. & inexp. & $p$-value & exp. & inexp. & $p$-value & exp. & inexp. & $p$-value & exp. & inexp. & $p$-value \\
\hline Baseline 1 & 7.20 & N/A & & 6.40 & N/A & & 8.00 & N/A & & 8.15 & 7.70 & \\
\hline Baseline 2 & 8.00 & N/A & & 8.80 & N/A & & 6.40 & N/A & & 8.51 & 6.98 & \\
\hline Baseline 3 & 10.40 & N/A & & 10.40 & N/A & & 8.00 & N/A & & 7.29 & 7.02 & \\
\hline Baseline 4 & 7.20 & N/A & & 9.60 & N/A & & 7.20 & N/A & & 11.67 & 7.87 & \\
\hline Baseline 5 & 8.80 & N/A & & 8.80 & N/A & & 10.40 & N/A & & 8.14 & 7.72 & \\
\hline avg. & 8.32 & N/A & & 8.80 & N/A & & 8.00 & N/A & & 8.75 & 7.46 & 0.031 \\
\hline \hline Inflow1/3_1 & 8.12 & 7.77 & & 7.09 & 9.82 & & 7.58 & 6.45 & & 12.34 & 6.53 & \\
\hline Inflow1/3_2 & 8.07 & 7.86 & & 7.43 & 6.74 & & 11.05 & 9.11 & & 8.37 & 9.66 & \\
\hline Inflow1/3_3 & 6.87 & 7.87 & & 9.92 & 4.16 & & 9.04 & 8.32 & & 6.44 & 6.33 & \\
\hline Inflow1/3_4 & 9.72 & 6.96 & & 9.81 & 9.18 & & 11.76 & 7.69 & & 9.30 & 7.80 & \\
\hline Inflow1/3_5 & 7.96 & 8.08 & & 7.75 & 6.10 & & 8.71 & 4.18 & & 8.03 & 7.95 & \\
\hline avg. & 8.15 & 7.70 & 0.313 & 8.40 & 7.20 & 0.250 & 9.63 & 7.15 & 0.031 & 8.90 & 7.65 & 0.156 \\
\hline \hline Inflow2/3_1 & 6.19 & 6.51 & & 7.00 & 6.10 & & 11.52 & 9.84 & & 7.11 & 4.85 & \\
\hline Inflow2/3_2 & 4.26 & 7.47 & & 6.60 & 6.30 & & 5.48 & 8.06 & & 7.03 & 8.49 & \\
\hline Inflow2/3_3 & 6.97 & 8.52 & & 6.91 & 6.15 & & 8.13 & 5.54 & & 8.05 & 9.18 & \\
\hline Inflow2/3_4 & 7.95 & 6.83 & & 16.39 & 7.41 & & 7.85 & 5.68 & & 8.96 & 6.32 & \\
\hline Inflow2/3_5 & 6.52 & 8.74 & & 7.59 & 5.81 & & 6.17 & 6.52 & & 6.25 & 7.68 & \\
\hline avg. & 6.38 & 7.61 & 0.938 & 8.89 & 6.35 & 0.031 & 7.83 & 7.13 & 0.281 & 7.48 & 7.30 & 0.438 \\
\hline
\end{tabular}

Table 6: Average Trade Volume by Experienced and Inexperienced Traders

(All Sessions and All Markets)

\begin{tabular}{|c|c|c|c|c|c|c|c|c|c|c|c|c|}
\hline & \multicolumn{3}{|c|}{ Market 1 } & \multicolumn{3}{|c|}{ Market 2 } & \multicolumn{3}{|c|}{ Market 3 } & \multicolumn{3}{c|}{ Market 4 } \\
\cline { 2 - 15 } Session & exp. & inexp. & $p$-value & exp. & inexp. & $p$-value & exp. & inexp. & $p$-value & exp. & inexp. & $p$-value \\
\hline Baseline 1 & 7.67 & N/A & & 6.83 & N/A & & 4.83 & N/A & & 2.75 & 9.00 & \\
\hline Baseline 2 & 8.00 & N/A & & 6.00 & N/A & & 5.00 & N/A & & 6.75 & 6.50 & \\
\hline Baseline 3 & 3.33 & N/A & & 2.33 & N/A & & 2.83 & N/A & & 1.88 & 3.75 & \\
\hline Baseline 4 & 5.67 & N/A & & 4.67 & N/A & & 5.83 & N/A & & 4.00 & 2.50 & \\
\hline Baseline 5 & 4.33 & N/A & & 2.50 & N/A & & 2.67 & N/A & & 3.25 & 4.00 & \\
\hline avg. & 5.80 & N/A & & 4.47 & N/A & & 4.23 & N/A & & 3.73 & 5.15 & 0.844 \\
\hline \hline Inflow1/3_1 & 7.88 & 6.25 & & 5.13 & 4.25 & & 5.00 & 2.50 & & 5.25 & 4.50 & \\
\hline Inflow1/3_2 & 7.63 & 1.25 & & 3.63 & 2.75 & & 6.88 & 4.25 & & 3.38 & 2.75 & \\
\hline Inflow1/3_3 & 5.50 & 5.00 & & 3.13 & 5.75 & & 2.75 & 1.50 & & 3.00 & 2.50 & \\
\hline Inflow1/3_4 & 11.88 & 2.25 & & 4.50 & 0.50 & & 4.50 & 4.50 & & 6.13 & 5.75 & \\
\hline Inflow1/3_5 & 3.13 & 1.75 & & 6.00 & 7.50 & & 5.50 & 5.50 & & 3.00 & 3.00 & \\
\hline avg. & 7.20 & 3.30 & 0.031 & 4.48 & 4.15 & 0.406 & 4.93 & 3.65 & 0.125 & 4.15 & 3.70 & 0.063 \\
\hline \hline Inflow2/3_1 & 3.25 & 3.88 & & 3.75 & 4.13 & & 4.00 & 3.75 & & 4.00 & 7.75 & \\
\hline Inflow2/3_2 & 5.25 & 6.38 & & 2.50 & 5.50 & & 7.00 & 6.00 & & 2.25 & 4.63 & \\
\hline Inflow2/3_3 & 9.75 & 5.13 & & 8.50 & 4.00 & & 7.50 & 7.50 & & 6.00 & 4.75 & \\
\hline Inflow2/3_4 & 6.00 & 4.75 & & 6.50 & 6.25 & & 4.75 & 3.63 & & 7.00 & 4.75 & \\
\hline Inflow2/3_5 & 6.50 & 4.25 & & 2.75 & 6.88 & & 5.50 & 4.25 & & 5.50 & 4.00 & \\
\hline avg. & 6.15 & 4.88 & 0.156 & 4.80 & 5.35 & 0.625 & 5.75 & 5.03 & 0.063 & 4.95 & 5.18 & 0.625 \\
\hline
\end{tabular}

